\title{
STUDI TRANSFORMASI PASAR TRADISIONAL, OBJEK STUDI PASAR CIPUTAT, KOTA TANGERANG SELATAN
}

\author{
Nelson Da Silva Pereira ${ }^{1)}$, Suryono Herlambang ${ }^{2)}$, Parino Rahardjo ${ }^{3)}$, Suryadi Santoso ${ }^{4)}$ \\ 1)Program Studi S1 PWK, Fakultas Teknik, Universitas Tarumanagara, pereira8293@gmail.com \\ 2)Program Studi S1 PWK, Fakultas Teknik, Universitas Tarumanagara, s.herlambang@gmail.com \\ 3)Program Studi S1 PWK, Fakultas Teknik, Universitas Tarumanagara, parinor19@gmail.com \\ 4)Program Studi S1 PWK, Fakultas Teknik, Universitas Tarumanagara, josantosojkt@yahoo.com
}

\begin{abstract}
Abstrak
Pasar Ciputat terletak di Jalan Aria Putra, dekat Flyover Ciputat. Dengan luas tanah 5.670 $\mathrm{m} 2$ dan luas bangunan $14.516 \mathrm{~m} 2$, Pasar Ciputat memiliki 4 level lantai, yaitu lantai Basement, lantai 1, lantai 2, dan lantai 3 yang berisi masjid serta kantor pengelola pasar, Dibangun oleh Pemerintah Daerah Kabupaten Tangerang pada tahun 1992 dan dikelola oleh Pemerintah daerah Dinas perdagangan dan Perdindustrian, Dari total 1.137 Kios dan loss hanya 441 kios dan 68 loss yang masih berjualan, Occupancy rate Pasar Ciputat ini adalah $37 \%$ saja, Diperkirakan sebanyak 698 kios dan 167 loss yang tutup, Kebanyakan pedagangg memilih untuk berjualan di lantai dasar atau di luar gedung pasar, tujuan dari penelitian ini adalah untuk mengetahui permasalahan yang ada di Pasar Ciputat dan mengetahui faktor yang menyebabkan banyaknya kios dan loss yang kosong di Pasar Ciputat, dilihat dari aksesisibilitas dan lokasi sekitar pasar, Pasar Ciputat cukup strategis, Pasar Ciputat adalah Pasar tradisonal yang kegiatan para penjual dan pembelinya dilakukan secara langsung dalam bentuk eceran dalam waktu sementara atau tetap dengan tingkat pelayanan terbatas, Penulis melakukan beberapa analisis seperti analisis kebijakan, analisis lokasi, analisis tapak, analisis pengunjung, analisis Pengelolaan, dan analisis best practice dengan metode deskritif dan metode SWOT, demi mengetahui apakah Pasar Ciputat tetap dipertahankan atau melakukan transformasi, dengan metode tersebut mentransformasi Pasar Ciputat adalah keputusan yang tepat untuk meningkatkan kualitas Pasar Ciputat.
\end{abstract}

\section{Kata kunci: Pasar Tradisional; Pengelolaan Pasar Tradisional; Transformasi Pasar} Tradisional

\begin{abstract}
Ciputat Market is located at Jalan Aria Putra, near Flyover Ciputat. With land area of 5,670 $\mathrm{m} 2$ and building area 14,516 m2, Ciputat market has 4 levels, namely Basement, floor 1, 2nd Floor, and 3rd floor that contains mosque and market management office, built by the local government of Tangerang Regency in 1992 and managed by the local Government of the trade and Perdindustrian, of a total of 1,137 stalls and loss of only 441 stalls and 68 loss that are still selling, the Occupancy rate of Ciputat market is $37 \%$, it is, estimated that as many as 698 stalls and 167 loss are closed, Most traders choose to sell on the ground floor or outside the market building, ttested from the research is to know the problems that exist in the market of ciputat and know the factors that cause the number of stalls and Loss are empty in Ciputat market, judging by the accessibility and location around the market, Ciputat market is strategic, Ciputat Market is a traditional market that the activities of the sellers and their buyers are carried out directly in the form of retail in the meantime or remain with a limited level of service, authors do some analysis such as policy analysis, location analysis, site analysis, visitor analysis, management analysis, and best Practice Analysis with Deskritif method and SWOT method, in orderto know that ciputat market is maintained or do transformation, with the method of transforming the market of Ciputat is the right decision to improve the quality of Ciputat market.
\end{abstract}

Keywords: traditional market; traditional market management; transformation of traditional markets 


\section{PENDAHULUAN}

\section{Latar Belakang}

Ciputat merupakan salah satu kecamatan di wilayah Tangerang Selatan yang menjadi pusat peradaban yang cukup penting karena berperan sebagai ibu kota Tangerang Selatan. Terdapat dua pasar tradisional yang cukup terkenal di Ciputat, yakni Pasar Ciputat dan Pasar Jombang. Pasar Ciputat terletak di Jalan Aria Putra, dekat Flyover Ciputat. Dengan luas tanah $5.670 \mathrm{~m} 2$ dan luas bangunan $14.516 \mathrm{~m} 2$, Pasar Ciputat memiliki 4 level lantai, yaitu lantai dasar, lantai 1, lantai 2, dan lantai 3 yang berisi masjid serta kantor pengelola pasar. Pasar ini buka setiap hari selama 24 jam. Dibangun oleh Pemerintah Daerah Kabupaten Tangerang pada tahun 1992 dan dikelola oleh Pemerintah daerah Dinas perdagangan dan Perdindustrian. Pasar ini didirikan untuk memenuhi kebutuhan akan pusat perdagangan sebagai dampak perkembangan wilayah Ciputat yang lokasinya cukup strategis dan merupakan pusat lalu lintas menuju Jakarta dari Tangerang Selatan.

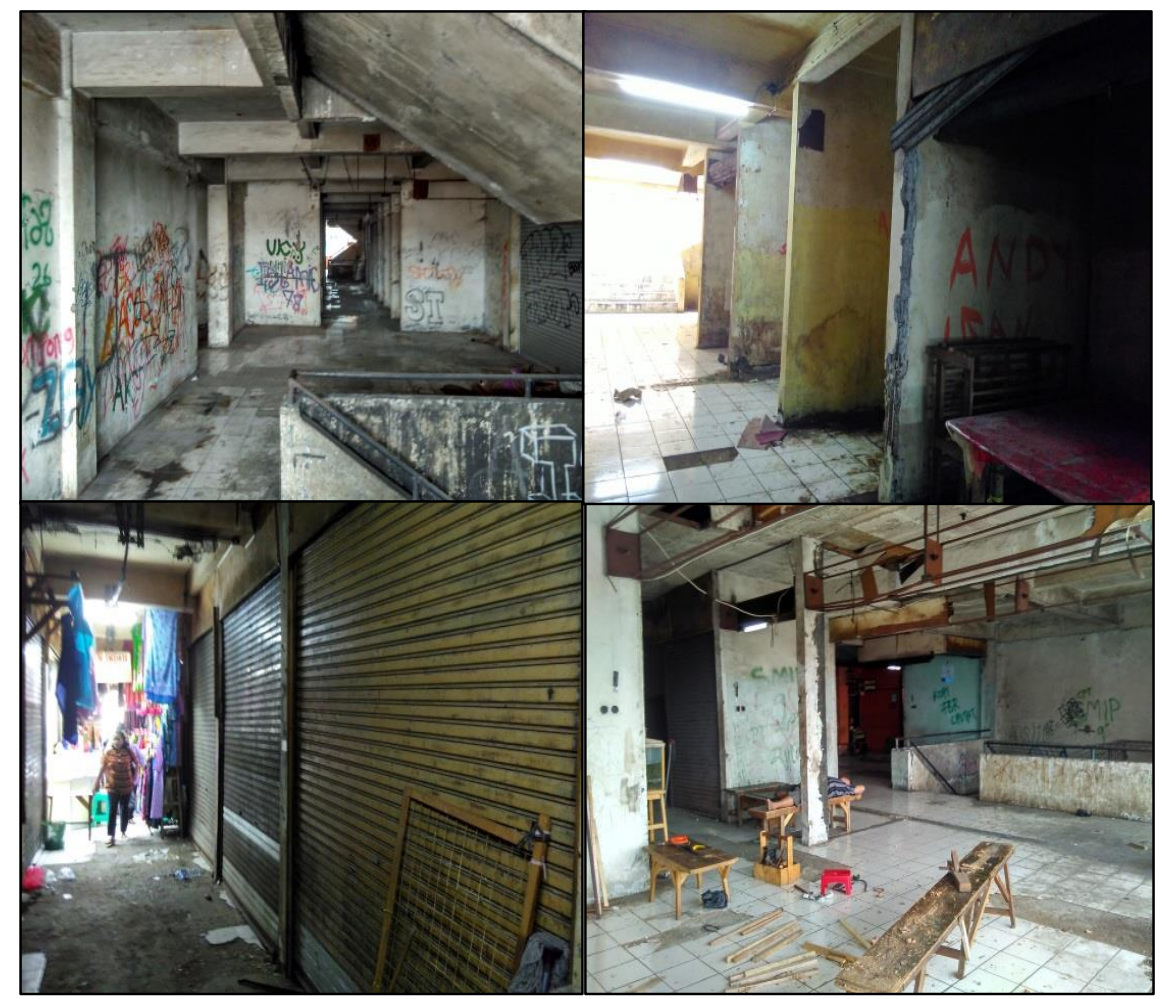

Gambar 1. Kondisi Pasar Ciputat

Sumber: Dokumentasi Penulis, 2019

Dari total 1.137 Kios dan los hanya 441 kios dan 68 loss yang masih berjualan. Occupancy rate Pasar Ciputat ini adalah 37\% saja. Diperkirakan sebanyak 698 kios dan 167 los yang tutup. Kebanyakan pedagangg memilih untuk berjualan di lantai dasar atau di luar gedung pasar. Dari gambar 1 dapat dilihat bahwa kondisi kios-kios di Pasar Ciputat tidak terorganisir dengan baik. Banyak pedagangg yang akhirnya memilih untuk berjualan di luar gedung dan menggunakan lahan parkir yang ada dan mengganggu mobilitas pengunjung yang membawa kendaraan. Hal ini membuat Pasar Ciputat ini lekat dengan istilah kotor dan macet.

Sehubungan dengan latar belakang tersebut maka dari uraian tersebut, dapat bahwa diperlukan adanya sebuah pembenahan pada Pasar Ciputat, yang baik dari segi kualitas dalam mewadahi aktivitas perdagangan masyarakat. Dengan begitu diharapkan para pelaku pasar (penjualpembeli) dapat dengan nyaman melakukan aktivitas transaksinya dengan nyaman. Oleh karena 
itu, untuk mengatasi permasalahan tersebut penulis melakukan studi terhadap Pasar Ciputat untuk bisa mencari solusi dari masalah yang terjadi di pasar tradisional.

\section{Rumusan Permasalahan}

Berlandaskan dari latar belakang di atas, berikut adalah poin-poin penting yang menjadi rumusan masalah dari penulisan makalah ini :

a. Kurangnya pengelolaan pasar yang benar sehingga Pasar Ciputat di lantai 2 dan 3 banyak tempat yang kosong.

b. Penjual Lebih memilih jual di pinggir jalan Pasar Ciputat karena harga sewa kios dan loss yang mahal.

c. Pengelolah kurang tegas dan membiarkan PKL untuk berjualan di sekitar bangunan pasar.

\section{Tujuan}

Tujuan dari penelitian ini adalah untuk mengetahui permasalahan yang ada di Pasar Ciputat dan mengetahui faktor yang menyebabkan banyaknya kios dan los yang kosong di Pasar Ciputat, dilihat dari aksesisibilitas dan lokasi sekitar pasar, Pasar Ciputat cukup strategis.

\section{KAJIAN LITERATUR}

Pasar adalah area tempat jual beli barang dengan jumlah penjual lebih dari satu baik yang disebut sebagai pusat perbelanjaan, pasar tradisional, pertokoan, mall, plasa, pusat perdagangan maupun sebutan lainnya. Pasar tradisional sebagai pasar yang dibangun dan dikelola oleh Pemerintah, Pemerintah Daerah, Swasta, Badan Usaha Milik Negara, dan Badan Usaha Milik Daerah termasuk kerjasama dengan swasta dengan tempat usaha berupa toko, kios, los, dan tenda yang dimilki/ dikelola oleh pedagangg kecil, menengah, swadaya masyarakat, atau koperasi dengan usaha skal kecil, menegah, dengan usaha skala kecil, modal kecil dan dengan proses jual beli barang dagangan melalui tawar menawar (Menteri Perdagangan Republik Indonesia). Ciri-ciri pasar tradisional menurut Permen No. 20 th. 2012 adalah sebagai berikut:

a. Pasar tradisional dimiliki, dibangun dan atau dikelola oleh pemerintah daerah.

b. Adanya sistem tawar menawar antara penjual dan pembeli.

Tawar menawar ini adalah salah satu budaya yang terbentuk di dalam pasar. Hal ini yang dapat menjalin hubungan sosial antara pedagangg dan pembeli yang lebih dekat.

c. Tempat usaha beragam dan menyatu dalam lokasi yang sama.

Meskipun semua berada pada lokasi yang sama, barang dagangan setiap penjual menjual barang yang berbeda-beda. Selain itu juga terdapat pengelompokan dagangan sesuai dengan jenis dagangannya seperti kelompok pedagangg ikan, sayur, buah, bumbu, dan dagin.

d. Sebagian besar barang dan jasa yang ditawarkan berbahan lokal.

Barang dagangan yang dijual di pasar tradisonal ini adalah hasil bumi yang dihasilkan oleh daerah tersebut. Meskipun ada beberapa dagangan yang diambil dari hasil bumi dari daerah lain yang berada tidak jauh dari daerah tersebut namun tidak sampai mengimport hingga keluar pulau atau negara.

\section{Jenis Pasar Tradisional}

Pasar sebagai perusahaan daerah digolongkan menurut beberapa hal, yaitu:

a. Menurut jenis kegiatannya, pasar digolongkan menjadi tiga jenis:

1) Pasar eceran, yaitu pasar dimana terdapat permintaan dan penawaran barang secara eceran.

2) Pasar grosir, yaitu pasar dimana terdapat permintaan dan penawaran dalam jumlah besar. 
3) Pasar induk, pasar ini lebih besar dari pasar grosir, merupakan pusat pengumpulan dan penyimpanan bahan-bahan pangan untuk disalurkan ke grosir- grosir dan pusat pembelian.

b. Menurut lokasi dan kemampuan pelayanannya, pasar digolongkan menjadi lima jenis:

1) Pasar Regional, yaitu pasar yang terletak di lokasi yang strategis dan luas, bangunan permanen, dan mempunyai kemampuan pelayanan meliputi seluruh wilayah kota bahkan sampai keluar kota, serta barang yang diperjual belikan lengkap dan dapat memenuhi kebutuhan masyarakatnya.

2) Pasar Kota, yaitu pasar yang terletak di lokasi strategis dan luas, bangunan permanen, dan mempunyai kemampuan pelayanan meliputi seluruh wilayah kota, serta barang yang diperjual belikan lengkap. Melayani 200.000-220.000 penduduk. Yang termasuk pasar ini adalah pasar induk dan pasar grosir.

3) Pasar Wilayah (Distrik), yaitu pasar yang terletak di lokasi yang cukup strategis dan luas, bangunan permanen, dan mempunyai kemampuan pelayanan meliputi seluruh wilayah kota, serta barang yang diperjual belikan cukup lengkap. Melayani 10.00015.000 penduduk. Yang termasuk pasar ini adalah pasar eceran.

4) Pasar Lingkungan, yaitu pasar yang terletak di lokasi strategis, bangunan permanen/ semi permanen, dan mempunyai pelayan meliputi permukiman saja, serta barang yang diperjual belikan kurang lengkap. Melayani 10.000-15.000 penduduk saja. Yang termasuk pasar ini adalah pasar eceran.

5) Pasar Khusus, yaitu pasar yang terletak di lokasi yang strategis, bangunan permanen/semi permanen, dan mempunyai kemampuan pelayanan meliputi wilayah kota, serta barang yang diperjual belikan terdiri dari satu macam barang khusus seperti pasar bunga, pasar burung, atau pasar hewan.

c. Menurut waktu kegiatannya, pasar digolongkan menjadi empat jenis:

1) Pasar siang hari yang beroperasi dari pukul 04.00-16.00.

2) Pasar malam hari yang beroperasi dari pukul 16.00-04.00.

3) Pasar siang malam yang beroperasi 24 jam nonstop.

4) Pasar darurat, yaitu pasar yang menggunakan jalanan umum atau tempat umum tertentu atas penentapan kepala daerah dan diadakan pada saat peringatan hari-hari tertentu. Seperti : pasar murah Idulfitri, pasar Maulud.

d. Menurut status kepemiliknnya, pasar digolongkan menjadi tiga jenis:

1) Pasar pemerintah, yaitu pasar yang dimiliki dan dikuasai oleh pemerintah pusat maupun daerah.

2) Pasar swasta, yaitu pasar yang dimiliki dan dikuasai oleh badan hukum yang diijinkan oleh pemerintah daerah.

3) Pasar liar, yaitu pasar yang aktivitasnya diluar oemerintahan daerah, yang kehadirannya disebabkan karena kurangnya fasilitas perpasaran yang ada dan letak pasar tidak merata, biasanya dikelola oleh perorangan/ ketua RW.

\section{Fasilitas Fisik Pasar Tradisional}

Menurut Peraturan Bupati Kabupaten Grobogan No.25 th 2011 fasiltas fisik pasar tradisional meliputi:

a. Elemen Utama. Salah satu elemen utama yang terdapat pada pasar yaitu ruang terbuka. Area ini biasanya digunakan sebagai tempat los-los pedagangg non permanen atau area parkir liar yang mulai marak muncul pada saat ini. Elemen utama yang lainnya yaitu ruang tertutup. Ruang tertutup yang dimaksud adalah ruangan yang tertutup atap namun tidak 
tertutup sepenuhnya oleh dinding atau penyekat ruangan lainnya. Contohnya seperti toko, kios, los, dasaran, kamar mandi, dan gudang.

b. Elemen Penunjang. Contoh elemen-elemen penunjang pada pasar tradsional yaitu area bongkar muat barang dagangan, dan pos penjaga.

c. Elemen Pendukung. Beberapa elemen pendukung yang ada di pasar adalah pusat pelayanan kesehatan, penitipan anak, pelayanan jasa, kantor pengelola pasar, koperasi pasar, tempat ibadah seperti mushola atau masjid.

d. Pencapaian.

e. Jaringan angkutan manusia dan barang.

f. Jaringan untilitas. Jaringan utilitas yang dimaksud adalah saluran listrik, air bersih, hydrant, komunikasi, dan sampah. Selain itu terdapat saluran- saluran air kotor dan limbah yang memenuhi kebutuhan pasar.

g. Area parkir.

h. Fasilitas sosial. Fasilitas sosial seringkali terlupakan pada pasar tradisional saat ini. Salah satu contoh sederhana fasilitas sosial yang dapat diaplikasikan pada pasar tradisional yaitu teras yang dapat digunakan sebagai interaksi sosial. Selain itu, pemberian vegetasi yang dapat dijadikan tempat berteduh dan menjalin interaksi sosial.

\section{Fasilitas Non Fisik Pasar}

Selain fasilitas fisik yang terdapat pada pasar tradisional, ada pula fasilitas non-fisik yang terdapat pada pasar tradisional seperti pengelolaan pasar, pelayanan dan pengawasan kesehatan dan kelengkapan komoditi yang tersedia dalam pasar.

\section{METODE}

\section{Teknik Pengolahan Data}

Analisis Kebijakan

Analisis kebijakan adalah proses untuk mendalami informasi sehingga menghasilkan rekomendasi kebijakan publik. Kebijakan publik merupakan keputusan dari pemerintah yang berpengaruh terhadap individu dalam kelompok masyarakat. Dalam penelitian ini analisis kebijakan digunakan untuk menganalisa kebijakan/perda tentang arahan Transformasi pasar Tradisional. Analisis Kebijakan ini akan menggunakan metode deskriptif.

\section{Analisis Lokasi}

Analisis lokasi merupakan analisis yang berdasarkan pada tiga unsur yakni jarak (proximity) dan akses untuk pergerakan. Dalam penelitian ini analisis lokasi digunakan untuk mengetahui struktur keruangan kawasan yang terdapat di Pasar Ciputat. Analisis Lokasi akan menggunakan metode deskriptif dan SWOT.

\section{Analisis Tapak}

Analsis tapak merupakan analisis yang berdasarkan faktor - faktor yang mempengaruhi karakter tapak. Dalam penelitian ini analisis tapak digunakan untuk mengetahui kesesuaian antara tapak dengan bangunan yang akan di bangun. Analisis tapak juga akan menggunakan metode deskriptif dan SWOT.

\section{Analisis Karakteristik Pengunjung}

Analisis persepsi pengunjung ini bertujuan untuk mengetahui karakteristik persepsi dan preferensi pengunjung yang datang Pasar Tradisional Ciputat terkait juga dengan rencana yang akan diterapkan di Pasar Tradisional Ciputat. Teknik pengolahan data yang dilakukan adalah deskriptif yaitu melakukan in depth interview dengan beberapa pengunjung, Penjual, dan Pengelola Pasar. 


\section{Analisis Pengelolaan}

Dalam analisis Pengelolaan bertujuan untuk mengetahui perang pengelola dalam menangani dagangan yang masih rame pengunjung, dan faktor yang menpengaruhi pedagang yang berjualan di diluar bangunan (PKL). Teknik pengolahan data yang dilakukan adalah deskriptif yaitu melakukan in depth interview dengan beberapa pengunjung, Penjual, dan Pengelola Pasar.

\section{Analisis Best Practice}

Analisis ini bertujuan untuk sebagai dasar acuan dengan produk atau konsep yang sama dengan objek penelitian, baik di dalam negeri maupun luar negeri. Benchmark yang dipilih adalah Pasar Mayestic, Jakarta. Teknik pengolahan data menggunakan benchmarking.

\section{Alat Analisis}

Metode Deskriptif

Metode deskriptif akan memperoleh gambaran tentang suatu hal dengan menggunakan datadata yang telah dikumpulkan dan kemudian menyajikannya dalam bentuk tabel maupun grafik. Tujuan dari alat analisis ini adalah data- data tersebut dapat disajikan dalam bentuk yang ringkas dan mudah dipahami.

\section{Metode SWOT}

Analisis SWOT membandingkan antara faktor eksternal (peluang dan ancaman) dengan faktor internal (kekuatan dan kelemahan) yang ada di Kawasan Wisata Pantai Bagedur. Ilustrasi bagaimana SWOT digunakan untuk menganalisa strategi untuk Merencana Pasar Tradisional Ciputat.

\section{DISKUSI DAN HASIL}

\section{Analisis Kebijakan Pasar Tradisional Dalam Rencana Tata Ruang Wialayah (RTRW) Kota Tangerang Selatan 2011-2031}

Kebijakan mengenai Rencana Tata Ruang Wilayah Kota Tangeran Selatan berdasarkan Peraturan Daerah Kota Tangeran Selatan Nomor 15 Tahun 2011 tentang Rencana Tata Ruang Wilayah Tahun 2011 - 2031. Dari analisis kebijakan di Tabel 1 dilihat bawah Pasar Ciputat masuk dalam rencana pengembangan pasar untuk pusat grosir dan tetap depertahan keberadaannya dan menjadi salah satu pasar tradisional yang memenui kebutahan masyarakat setempat.

Table 1. Tabel Analisis Kebijakan

\begin{tabular}{|c|c|c|}
\hline \multicolumn{2}{|c|}{ Peraturan Daerah Kota Tangerang Selatan no 15 Tahun 2011} & \multirow[b]{2}{*}{ Realisasi } \\
\hline Pasal Ayat & Kebijakan & \\
\hline Pasal 48 ayat 1 & $\begin{array}{l}\text { peruntukan perdagangan dan jasa } \\
\text { sebagaimana dimaksud dalam pasal } 46 \text { uruf } \\
\text { b meliputi: Pasar Tradisional, pusat } \\
\text { perbelanjaan, dan toko modern. }\end{array}$ & $\begin{array}{l}\text { Rencana pemerintah untuk } \\
\text { mengembangan Kawasan } \\
\text { perdagangan dan salah satunya pasar } \\
\text { Tradisional dengan untuk } \\
\text { meningkatkan pasar Tradisional yang } \\
\text { baik untuk menlayani masyarakat } \\
\text { kota Tangerang selatan. }\end{array}$ \\
\hline \multirow[t]{5}{*}{ Pasal 48 ayat 2} & $\begin{array}{l}\text { Pasar tradisional sebagaimana dimaksud } \\
\text { pada ayat (1) huruf a meliputi : }\end{array}$ & $\begin{array}{l}\text { Pasar Trdasional ciputat masuk } \\
\text { dalam rencana tata ruang wilayah }\end{array}$ \\
\hline & a) Pasar Ciputat di Kecamatan Ciputat; & Tangerang Selatan dengan \\
\hline & $\begin{array}{l}\text { b) Pasar Ciputat Permai di Kecamatan } \\
\text { Ciputat; }\end{array}$ & $\begin{array}{l}\text { ditetapkan sebagai salah satu pasar } \\
\text { tradisional yang akan di kembangkan }\end{array}$ \\
\hline & $\begin{array}{l}\text { c) pasar Jombang di Kecamatan } \\
\text { Ciputat; }\end{array}$ & $\begin{array}{l}\text { namun sampai saat ini belom ada } \\
\text { rencana yang pasti untuk Pasar }\end{array}$ \\
\hline & $\begin{array}{l}\text { d) pasar Bintaro Sektor } 2 \text { di } \\
\text { Kecamatan Ciputat Timur; } \\
\text { e) pasar Jengkol di Kecamatan Setu; }\end{array}$ & $\begin{array}{l}\text { Ciputat, di lihat dari akssesibilitas } \\
\text { Pasar Ciputat adalah salah satu pasar }\end{array}$ \\
\hline
\end{tabular}




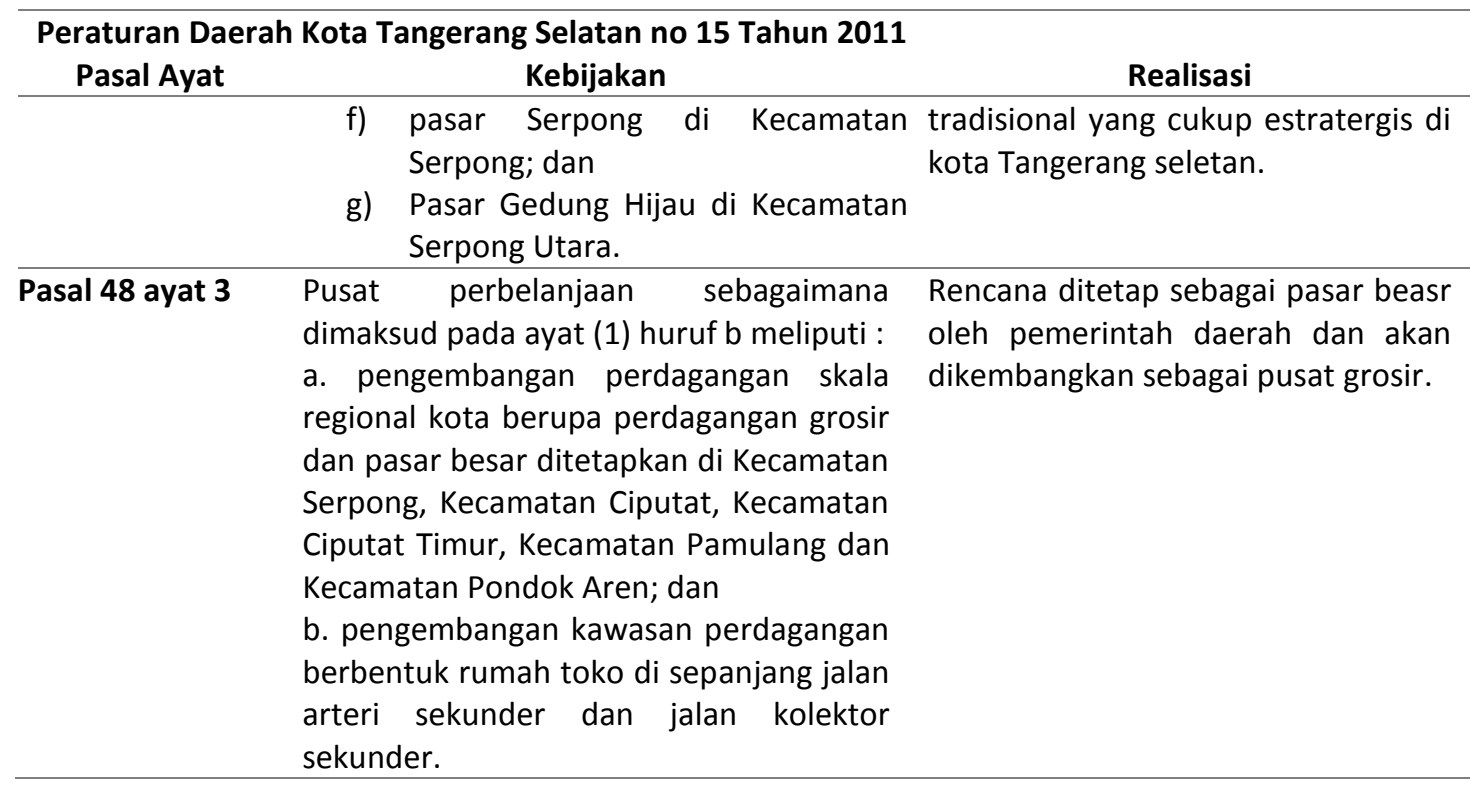

\section{Analisis Lokasi}

Kesimpulan dari analisis lokasi Pasar Ciputat menggunakan SWOT dalam Tabel 2, yaitu pasar memiliki lokasi yang strategis, dan dalam rencana pemerintah daerah Tangerang Selatan RTRW Pasar Ciputat akan tetap di pertahankan sebagai pasar tradisional, dan mentrasnformasi pasar adalah salah satu solusi untuk meningkatkan kualitas pasar dan menberih kenyaman bagi pembelih maupun pedagang di dalam Pasar Ciputat tersebut.

Tabel 2. Analisis SWOT

\begin{tabular}{|c|c|c|}
\hline & Strength (S) & Weakness (W) \\
\hline Eksternal & $\begin{array}{l}\text { - Lokasi pasar sanggat } \\
\text { strategis berada di jalan } \\
\text { kolektor arteri dan lokal. } \\
\text { - Berada lingkungan yang } \\
\text { bagus yang didominasi oleh } \\
\text { perumanahan dan } \\
\text { apartemen. } \\
\text { - Maioritas pembelih adalah } \\
\text { masyarakat kecamatan } \\
\text { ciputat. }\end{array}$ & $\begin{array}{l}\text { - KDB yang terlalu tinggi sehigga } \\
\text { kurangnya lahan parkir untuk } \\
\text { kendaraan. } \\
\text { - Pengelolah yang kurang tegas } \\
\text { dan menbiarkan PKL di ruas jl H. } \\
\text { Usman } \\
\text { - Perawatan bangunan yang } \\
\text { kurang. }\end{array}$ \\
\hline $\begin{array}{l}\text { Oportunity (O) } \\
\text { - Pasar Ciputat masuk dalam } \\
\text { rencana tata ruang wilayah } \\
\text { Tangerang Selatan dengan } \\
\text { ditetapkan sebagai salah } \\
\text { satu pasar tradisional yang } \\
\text { akan di kembangkan pasal } \\
48 \text { ayat } 2 . \\
\text { - Pasar Ciputat sudah masuk } \\
\text { dalam rencana Revitalisasi } \\
\text { Pasar tradisional } \\
\text { Pemerintah daerah Tangsel }\end{array}$ & \begin{tabular}{l}
\multicolumn{1}{c}{$\mathrm{S}-\mathrm{O}$} \\
- \\
pemanfatkan lokasi \\
kemudaan aksesibilitas \\
bagi pembelih dan \\
pedagang \\
- Meninkatkan kuatlitas \\
pasar dengan revitalisasi \\
yang lebih higienis dan \\
teratur
\end{tabular} & $\begin{array}{l}\text { W - O } \\
\text { - Menredesain agar pengunaan } \\
\text { lahan Pasar Ciputat lebih optimal } \\
\text { - Pengelola harus lebih tegas } \\
\text { menangapi PKL untuk bisa } \\
\text { meningkatkan Ocupancy rate } \\
\text { pasar. } \\
\text { - Pengelola Pasar harus lebih } \\
\text { meningkatkan perawatan } \\
\text { bangunan, kebersihan dan } \\
\text { peraturan dalam pasar. }\end{array}$ \\
\hline $\begin{array}{l}\text { Threats }(\mathrm{T}) \\
\text { - Keberadaan Pasar } \\
\text { moderren yang di sekitar } \\
\text { pasar tradisional }\end{array}$ & \begin{tabular}{l}
\multicolumn{1}{c}{$\mathrm{S}-\mathrm{T}$} \\
- Menbuat strategi yang \\
dapat mendukung Pasar \\
Ciputat sehingga dapat \\
menarik pengunjung
\end{tabular} & 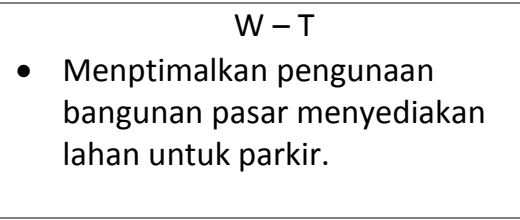 \\
\hline
\end{tabular}




\begin{tabular}{lll}
\hline & \multicolumn{1}{c}{ Strength $(\boldsymbol{S})$} & \multicolumn{1}{c}{ Weakness $(\boldsymbol{W})$} \\
\hline - PKL yang selalu ada (bandel) & untuk masuk ke dalam & - \\
di sekitar pasar. & pasar, seperti & pengelolah untuk mengadapi \\
& memperbanyak tenant & PKL, Pasar Moderen dan \\
& atau memindahkan PKL ke & pengelolaan peraturan \\
& dalam Gedung. & banugunan. \\
\hline
\end{tabular}

Sumber: Olahan Penulis, 2020

\section{Analisis Tapak}

Analisis ini bertujuan untuk melihat karakteristik di objek studi sehingga dapat dilakukan strategi dalam melakukan penataan.

Tabel 3. Analisis Tapak

\begin{tabular}{|c|c|c|c|}
\hline Aspek & Analisis Lokasi & Analisis Tapak & Keluaran analisis \\
\hline Asesibilitas & $\begin{array}{l}\text { Pasar Ciputat memiliki } \\
\text { akses yang bagus } \\
\text { karena berada di jalan } \\
\text { lokal, kolektor, dan } \\
\text { arteri, sehingga } \\
\text { terdapat banyak } \\
\text { angkutan umum yang } \\
\text { melewatinya. }\end{array}$ & $\begin{array}{l}\text { Tapak memiliki akses ke jalan } \\
\text { yang bagus memiliki } 4 \text { pintu } \\
\text { masuk yang beradapan ke } \\
\text { jalan kolektor aria putra, dan } 2 \\
\text { pintu ke jalan lokal H. Usman, } \\
\text { dan ada } 2 \text { pintu masuk yang } \\
\text { satu dari permukiman warga } \\
\text { ke Blok AK, dan yang kedua } \\
\text { dari parkiran motor yang bisa } \\
\text { di akses dari plaza ciputat. }\end{array}$ & $\begin{array}{l}\text { Tapak memiliki askses yang } \\
\text { baik dari segi transportasi } \\
\text { umum maupun segi akses ke } \\
\text { bangunan Pasar Ciputat. }\end{array}$ \\
\hline $\begin{array}{c}\text { Lingkungan } \\
\text { Sekitar } \\
\text { Tapak }\end{array}$ & $\begin{array}{l}\text { Pasar Ciputat berada di } \\
\text { lingkungan yang } \\
\text { didominasi hunian, } \\
\text { seperti apartemen, } \\
\text { perumahan Kedaun } \\
\text { hijau dan permukiman } \\
\text { lainnya. }\end{array}$ & $\begin{array}{l}\text { Faktor kurangnya pengelolaan } \\
\text { dan peraturan terhadap PKL } \\
\text { sheingga membuat Pasar } \\
\text { Ciputat sepih dengan } \\
\text { pengunjun. Di lihat dari } \\
\text { lingkungan sekitar tapak, } \\
\text { Pasar Ciputat berdekatan } \\
\text { dengan banyak hunian mau } \\
\text { hunian landed atau orizontal. }\end{array}$ & $\begin{array}{l}\text { Pasar Ciputat berada di } \\
\text { lingkungan yang sangat } \\
\text { bagus dan estrategis } \\
\text { dikelilingi oleh hunian dan } \\
\text { sehingga bisa aksesibilitas } \\
\text { yang sangat memadahi, } \\
\text { harusnya Pasar Ciputat } \\
\text { meningkatkan kualiatas } \\
\text { pasar dan peraturan yang } \\
\text { agar PKL tidak ada lagi. }\end{array}$ \\
\hline $\begin{array}{l}\text { Analisis } \\
\text { Dalam } \\
\text { Tapak }\end{array}$ & $\begin{array}{l}\text { Dilihat dari segi lokasi } \\
\text { tapak berada pada } \\
\text { aksesibilitas yang } \\
\text { bagus dan sangat } \\
\text { mendukung pasar. }\end{array}$ & $\begin{array}{l}\text { Sekitar tapak terdapat banyak } \\
\text { PKL yang berjualan di pinggir } \\
\text { jalan atau mengunakan } \\
\text { trotoar sebagai sebagai } \\
\text { tempat berjualan sehingga } \\
\text { meninbulkan kemacetan pada } \\
\text { jam kerja dan pulang kerja. }\end{array}$ & $\begin{array}{l}\text { Kurangnya pengelolah dan } \\
\text { kurang tegas dari } \\
\text { pemerintah daerah sehingga } \\
\text { menbuat PKL banyak di } \\
\text { pingir jalan H. Usman } \\
\text { menbuat kemacetan. }\end{array}$ \\
\hline $\begin{array}{c}\text { Analasis } \\
\text { Pengunaan } \\
\text { Bangunan }\end{array}$ & $\begin{array}{l}\text { Kebanyakan penjual } \\
\text { adalah masyarakat } \\
\text { Ciputat dan sekitarnya. } \\
\text { Tapi karena harga } \\
\text { sewa yang mahal dan } \\
\text { kurangnya perawatan } \\
\text { Gedung sehingga } \\
\text { masyarakat lebih } \\
\text { memilih bejualan di } \\
\text { pingir jalan yang lebih } \\
\text { murah hanya bayar } \\
\text { uang listrik dan } \\
\text { pemungutan liar. }\end{array}$ & $\begin{array}{l}\text { Kurangnya pengelolahan } \\
\text { pasar yang sehingga } \\
\text { menimbulkan banyak kios dan } \\
\text { los yang kosong, dan harga } \\
\text { sewa yang mahal, sehingga } \\
\text { pedagang lebih memilih } \\
\text { berjualan di pinggir jalan yang } \\
\text { biaya lebih murah dari sewa } \\
\text { kios atau los }\end{array}$ & $\begin{array}{l}\text { Faktor kurangnya penjual } \\
\text { dan pembelih di dalam } \\
\text { bangunan karena banyak kios } \\
\text { dan loss yang Sudah dibelih } \\
\text { dengan jangka waktu } 30 \\
\text { tahun. Kepada pta beatania } \\
\text { multi srana. sehigga pada } \\
\text { tahun } 2017 \text { pemrintah } \\
\text { mengabil ahli pengelolah } \\
\text { pasar. Karena ada yang } \\
\text { punyak hak pakai sampe } 30 \\
\text { tahun jadi pemerintah tidak } \\
\text { bisa melakukan renovasi } \\
\text { terhadap Pasar Ciputat. }\end{array}$ \\
\hline
\end{tabular}

Sumber: hasil olahan, 2020 
Dari hasil analisis analisis lokasi dan tapak di Tabel 3 dapat disumpulkan bawah lokasi pasar tidak menpengaruhi sepihnya pasar, dan aksesibilitas sangat bagus dan lokasi sekitar pasar juga maioritas Hunian, warung dan restoran. Faktot Sepihnya Pasar Ciputat karena keberadaan PKL dan kurang tegasnya pengelolah menangani PKL sehingga menbuat Pasar Ciputat sepih pengunjung dan pedagangg.

\section{Analisis Karekteristik Pengunjung}

Analisis karakteristik pengunjung bertujuan untuk mengetahui dagangan yang masih rame pengunjung di Pasar Ciputat, mengetahui keperluan pengunjung di pagi hari dan pada malam.

Tabel 4. Pengunjung Jam 00:00-06:00

\begin{tabular}{|c|c|c|c|}
\hline PKL & Lt Basement & Lt 1 & Lt 2 \\
\hline $\begin{array}{l}\text { - Maioritas pemilik } \\
\text { warung makan, dan } \\
\text { Pedangan gerobak kelilin }\end{array}$ & $\begin{array}{l}\text { - Maioritas pemilik warung } \\
\text { makan, dan Pedangan } \\
\text { gerobak kelilin }\end{array}$ & - Tutup & - Tutup \\
\hline $\begin{array}{l}\text { - Sayur mayur, bumbu } \\
\text { dapur, dagin. } \\
\text { - Untuk dijual Kembali. } \\
\text { - Jumlah pengunjung } 200 \\
\text { lebih }\end{array}$ & $\begin{array}{l}\text { - Sayur mayur, bumbu dapur, } \\
\text { dagin. } \\
\text { - Untuk dijual Kembali. } \\
\text { - Jumlah pengunjung } 100 \\
\text { lebih }\end{array}$ & & \\
\hline
\end{tabular}

Sumber: olahan penulis, 2020

Tabel 5. Pengunjung Jam 06:00-24:00

\begin{tabular}{|c|c|c|c|}
\hline PKL & Lt Basement & Lt 1 & Lt 2 \\
\hline $\begin{array}{l}\text { - Maioritas ibu rumah } \\
\text { tangga, pelajar } \\
\text { - Sayur mayur, bumbu } \\
\text { dapur, dagin. Jajanan } \\
\text { - Untuk keperluan } \\
\text { sendiri } \\
\text { - Jumlah pengunjung } \\
200 \text { lebih }\end{array}$ & $\begin{array}{l}\text { - } \quad \text { Ibu rumah tangga } \\
\text { - } \quad \text { Untuk keperluan dapur dagin } \\
\text { sendiri } \\
\text { - Jumlah Pengunjung } \\
20 \text { lebih }\end{array}$ & $\begin{array}{l}\text { - Mahasiswa, pelajar } \\
\text { - Sandang, ATK, dan } \\
\text { Acessoris. } \\
\text { - Keperluan pribadi } \\
\text { - Jumlah Pengunjung } \\
70 \text { lebih }\end{array}$ & $\begin{array}{l}\text { - Pelajar mahasiswa } \\
\text { dan ibu rumah } \\
\text { tangga } \\
\text { - Pakaian Muslimah, } \\
\text { sepato acessoris, } \\
\text { - Keperluan sendiri } \\
\text { - Jumlah Pengunjung } \\
70 \text { lebih }\end{array}$ \\
\hline
\end{tabular}

Sumber: Olahan Penulis, 2020

Dilihat dari tabel salah satu faktor yang menpengaruhi pasar sepih adalah adirnnya para PKL yang berada di sekitar tapak Pasar Ciputat. Lantai basement occupancy rate $38 \%$ karena semua pedagangan lebih memilih berjualan di pingir jalan, untuk lantai basement sendiri diperuntukan untuk jualan sayur dagin ,buah, dan bumbu dapur. Namun hadirnya PKL yang berjualan yang sama jadi menbuat lantai basement sepih pengunjung.

\section{Analisis Pengelolaan}

Dalam analisis Pengelolaan bertujuan untuk mengetahui perang pengelola dalam menangani dagangan yang masih rame pengunjung, dan faktor yang menpengaruhi pedagang yang berjualan di diluar bangunan (PKL).

Tabel 6. Harga Sewa Kios dan Biya Untuk PKL

\begin{tabular}{lccccl}
\hline \multicolumn{1}{c}{ Tempat } & $\begin{array}{c}\text { Harga Sewa } \\
\text { /Tahun }\end{array}$ & $\begin{array}{c}\text { Listrik } \\
\text { /Tahun }\end{array}$ & $\begin{array}{c}\text { Keamanan } \\
\text { /Tahun }\end{array}$ & $\begin{array}{c}\text { Kebersihan } \\
\text { /Tahun }\end{array}$ & $\begin{array}{l}\text { Jumlah Total } \\
\text { /Tahun }\end{array}$ \\
\hline $\begin{array}{l}\text { Pedagang } \\
\text { Dalam } \\
\text { Bangunan }\end{array}$ & $\mathrm{Rp} 5.000 .000$ & $\mathrm{Rp} 1.095 .000$ & $\mathrm{Rp} \mathrm{3.285.000}$ & $\mathrm{Rp} \mathrm{730.000}$ & $\mathrm{Rp} \mathrm{10.110.000}$ \\
\hline PKL & & & & & \\
\hline
\end{tabular}

Sumber: olahan penulis 
Dilihat dari Tabel 6 bahwa harga sewa untuk pedagang yang didalam bangunan sangat tinggi namun fasilitas yang mereka dapat kurang, untuk PKL sendiri pengelolah menfasilitasi listrik, keamanan dan kebersihan. Dilihat dari harga sewa itulah menbuat banyak pedagang lebih memilih berjualan di luar bangunan. PKL maioritas pedagang yang berdagang di dalam pasar yang pindah keluar.

Namun untuk lantai basement occupancy rate sangat rendah di karenakan berjualan sama dengan PKL yang di sekitar pasar yang mayoritas berjualan sayur mayur, untuk lantai 1 dan 2 meskipun occupancy rate hanya $43 \%$ dan $31 \%$ tapi masih cukup rame pengunjun dapat dilihat di tabel karena di lantai 1 dan lantai pedagang maioritas jualan pakaian, acessesoris, tas, sepatu, dan jam, meskipun ada Ramayana di dekat pasar, namun pengunjung lebih memilih belih di pasar karena bisa tawar dan menawar soal harga

\section{KESIMPULAN DAN SARAN}

\section{Kesimpulan}

Salah satu faktor yang occupancy rate Pasar Ciputat rendah bawah harga sewa untuk pedagang yang didalam bangunan sangat tinggi namung fasilitas yang mereka dapat kurang, untuk PKL sendiri pengelolah menfasilitasi listrik, keamanan dan kebersihan. Dilihat dari harga sewa itulah menbuat banyak pedagang lebih memilih berjualan di luar bangunan. PKL maioritas pedagang yang berdagang di dalam pasar yang pindah ke luar. Namun untuk lantai basement occupancy rate dan pengunjung sangat rendah di karenakan berjualan sama dengan PKL yang di sekitar pasar yang maioritas berjualan sayur mayur, untuk lantai 1 dan 2 meskipun occupancy rate hanya $43 \%$ dan $31 \%$ tapi masih cukup rame pengunjun dapat dilihat di tabel 5.8 karena di lantai 1 dan lantai 2 pedagang maioritas jualan pakaian, acessesoris, tas, sepatu, dan jam, meskipun ada Ramayana di dekat pasar, namun pengunjung lebih memilih belih di pasar karena bisa tawar dan menawar.

\section{Saran}

Dari penelitian yang telah dilakukan diatas adapun hal yang dapat dijadikan rekomendasi atau saran untuk mengembalikan dan menghidupkan Pasar Ciputat terutama Pedangan dalam Pasar, yaitu:

a. Mentransformasi Pasar Ciputat, untuk meningkatkan kualitas pasar agar bisa meningkatkan Ocupanccy rate Pasar.

b. Menyediakan fasilitas pendukung, seperti lahan parkir untuk menampung kendaraan seperti motor dan mobil.

c. Diperlukan kerjasama antara pemilik Kios dan pengelolah Pasar terkait dengan redesain bangunan Pasar Ciputat dengan menjadikan lantai baasement sebagai Tempat parkir, dan Pengelolah tegas dengan memindakan PKL ke dalam bangunan agar tidak ada PKL yang berjualan di trotoar Pasar Ciputat, sehingga tidak menggangu sirkulasi dan aksesisbilitas sekitar Tapak.

d. Diperlukan kerjasama dan koordinasi antara pihak Pengelolah Pasar dan Plaza Ciputat, untuk mengunakan area parkir Plaza ciputat untuk parkir pengunjung Pasar Ciputat, jika opsi redesain pasar tidak oleh Pemilik kios kios yang ada Di lantai basement.

\section{REFERENSI}

Belshaw, C. S. (2009). Tukar Menukar Di Pasar Tradisional dan Modern.

Fuad, M. d. (2000). Pengantar bisnis. Jakarta: Penerbit PT Gramedia.

Galuh, O. (2007). Redesain Pasar Jongke Surakarta. Universitas Atma Jaya: Skripsi S-1.Fak. Teknik, Jur. Arsitektur.

Heri, A. (n.d.). Menahan Serbuan Pasar Modern. 94-96. 
KMK. (2008). Tentang Pedoman Penyelanggaraan Pasar Sehat . p. 59.

Bupati, P. (2011). Perbup. Kabupaten Grobogan no.25 th 2011. Kabupaten Grogogan: Peremerintah Daerah.

Menteri Kesehatan Republik Indonesia. (2008). Penyelenggaraan Pasar Sehat Nomor: 519/Menkes/Sk/Vi/2008. Indonesia.

Peraturan Pemerintah (2007). Penataan Dan Pembinaan Pasar Tradisional. Indonesia.

Pengaturan, Pengelolaan, dan Pengembangan Citra Pasar Tradisional Di Wilayah Perkotaan dan Perdesaan. (2007). pp. 35-38.

Peraturan Menteri Pekerjaan Umum. (2010). Pedoman Revitalisasi Kawasan. Indonesia: Peraturan Menteri Pekerjaan Umum No. 18.

Perhub. Kab. Grobogan. (2011). Peraturan Daerah. Grobogan, Indonesia.

Peraturan Menteri Dalam Negeri Republik Indonesia. (2012). Pengelolaan Dan Pemberdayaan Pasar Tradisional. Indonesia.

Peraturan Daerah Yogyakarta. (2001). Peraturan Tentang Pasar, 2.

Defenisi Revitalisasi. (2009). Retrieved from Makalahdanskripsi.blogspot.com : http://makalahdanskripsi.blogspot.com/2009/03/definisi-revitalisasi.html

Pasar Ciputat Bakal Seperti Blok M, Estimasi Anggaran Rp 300 Miliar. (2018). Retrieved from Kompas.com: https://megapolitan.kompas.com/read/2018/10/28/21065741/pasarciputat-bakal-seperti-blok-m-estimasi-anggaran-rp-300-miliar 
